\title{
An Entrepreneurially Minded Learning (EML) Module Involving Global Markets for Medical Devices Implemented in an Engineering Physiology Course
}

\section{Dr. Michael J Rust, Western New England University}

Michael J. Rust received his B.S. and Ph.D. degrees in Electrical Engineering from the University of Cincinnati, Cincinnati, OH, in 2003 and 2009, respectively. During his undergraduate training, he worked for Ethicon Endo-Surgery and AtriCure, companies that specialize in the development of novel surgical devices. While completing his doctoral dissertation, Dr. Rust served as an NSF GK-12 Graduate Fellow, which allowed him to develop hands-on engineering activities for high school students. In 2009, he joined the faculty of Western New England University where he currently holds the position of Associate Professor of Biomedical Engineering. He teaches undergraduate courses in bioinstrumentation, physiology, lab-on-a-chip, and global health. Dr. Rust has published numerous papers in professional conferences and technical journals, and he is a co-inventor on four US patents. He is a member of the Institute for Electrical and Electronics Engineers (IEEE) and the American Society for Engineering Education (ASEE). Dr. Rust's work has been funded by the National Science Foundation (NSF), National Institutes of Health $(\mathrm{NIH})$, American Society for Quality (ASQ), Kern Entrepreneurial Engineering Network (KEEN), and the Jenzabar Foundation. His research interests involve the development of point-of-care medical technologies, including bioinstrumentation for use in low-resource settings. Dr. Rust is the co-founder and Chief Technical Officer at New England Breath Technologies, which is developing a non-invasive breathalyzer for diabetes care. 


\title{
An Entrepreneurially Minded Learning (EML) Module Involving Global Markets for Medical Devices Implemented in an Engineering Physiology Course
}

\begin{abstract}
A global market case study involving entrepreneurially minded learning (EML) was developed and implemented in an engineering physiology course. The module presented a scenario to students in which a company is considering taking an existing medical device (e.g., blood glucometer) into new markets. The central question of the assignment is whether there is a global market for this product, or if it is only suitable for use in the domestic market. Students were assigned a particular region/country of the world to explore (e.g., Europe, South America, Asia, etc.), including metrics to investigate such as clinical relevance, economics, and technical feasibility. Ultimately, the students were asked to provide a recommendation as to whether there is a market opportunity to exploit, or if the device should remain in the U.S. marketplace. The results from student-reported survey data showed the module had a positive impact on perceived EML skill development. Additionally, analysis of technical questions showed the module improved student understanding of the underlying physiology and clinical relevance, which were topics retained from the original course content prior to the implementation of this intervention.
\end{abstract}

\section{Introduction}

Biomedical engineering (BME) is a demanding field of study since students must develop not only technical skills in engineering, but also a solid understanding of human physiology. This has often been addressed in the BME curriculum by the inclusion of stand-alone courses in anatomy and physiology, which attempt to provide students with the background knowledge needed to be successful in the medical field [1]. Depending on the institution, these physiology courses are often taught by faculty in the Biological Sciences or the BME faculty themselves. In either case, the large volume of anatomical structures and physiological principles covered in these courses can make them quite challenging for students, especially considering how different this type of content is from other engineering courses (e.g., instrumentation, materials science, etc.) $[2,3]$. Moreover, many students struggle in these medically-focused courses to make connections between the underlying physiology and their work as engineers (e.g., development of a medical device that diagnoses/treats a pathology related to that physiology). As a result, modules are sought that connect physiology course content to existing or new medical technologies in an authentic, active-learning format. 
Here, we describe a new module that uses entrepreneurially minded learning (EML) to engage BME students in a case study involving global markets for medical devices. EML is an attractive approach since it allows students to express their curiosity, make connections between different subjects, and ultimately explore value creation in a number of ways $[4,5,6]$. For example, EML has been incorporated in first year engineering courses such as Introduction to Engineering [4] as well as second-year foundational course such as Statics and Probability \& Statistics [7]. EML has also been applied to major-specific courses such as Fluid Mechanics [5].

EML has also been shown to improve student learning as well as lead to increased perception of skills related to the entrepreneurial mindset in engineering courses, in general [7, 8, 9, 10]. For example, students showed gains in various EML skills when engaged in modules related to failure analysis case studies such as the Hyatt Regency Hotel Walkway Collapse [7]. Similar gains were demonstrated when students conducted market research for a fictitious company looking to locate a new fabrication facility near growing population centers [7].

It should be noted that BME courses, in particular, present a unique opportunity to leverage the benefits of EML. Due to the nature of their work, biomedical engineers are often tasked with being the connecting link in the medical device industry between clinicians, scientists, and patients. Thus, the potential for EML to provide opportunities for BME students to make connections between physiological models (such as a disease state), technical concepts (devices for diagnosis/therapy), and markets are highly valuable.

\section{Activity Details}

The newly developed EML module was implemented in a junior-level engineering physiology course at Western New England University (WNE), a small, private university in the Northeast region of the U.S. The course title is Engineering Physiology II (BME 302), and it is a required course in the BME curriculum at WNE that is typically taken by third-year BME students. The main course topics, which builds on content in Engineering Physiology I, involves the study of systems physiology, including the nervous, cardiovascular, respiratory, renal, and digestive systems. The module described in this work was developed to support learning related to diabetes mellitus, which is a condition that affects all five physiological systems studied throughout the course. As a result, the module was implemented during the final week of the course to help tie together the various physiological systems and show how one disease can have an impact on all of them.

In the new module, titled "Global Markets: Diabetes," students were introduced to the group of conditions known as diabetes mellitus through a set of lecture notes. Topics in these lecture notes included disease statistics and the underlying physiology as it relates to the hormone insulin. It should be noted that this material was covered in the previous offerings of the course prior to the intervention described here, and is the only such content holdover in the module. Next, lecture 
notes were provided regarding the diagnosis, monitoring, and treatment of diabetes, as well as pathologies and complications across the nervous, cardiovascular, respiratory, renal, and digestive systems. Subsequently, students were presented a scenario involving a company that is considering taking an existing medical device into new markets. The device in question was a blood glucometer, which is used for monitoring blood sugar levels for patients with diabetes, and was also discussed in the aforementioned lecture notes.

The problem statement that was posed to the students asked whether there is a global market for this product, or if it is only suitable for use in the domestic (U.S.) market. Students worked in teams of 3-4 students; these teams were formed earlier in the semester for other in-class teamwork and were continually used throughout the semester. Each team was assigned a particular country of the world to explore, including one in Asia (Japan), Africa (Morocco), Central America (Guatemala), and South America (Brazil). The teams were given a set of metrics to investigate for their assigned country, including (1) clinical relevance, (2) economics, and (3) technical feasibility. Notes on how to go about investigating each of these metrics were provided along with the information on diabetes mellitus described earlier [11]. Ultimately, the teams were asked to provide a recommendation as to whether there is a market opportunity to exploit in their assigned country, or if the company would be better served focusing on the U.S. marketplace. Each team made their recommendation in the form of a one-page memo that outlined their recommendation, which needed to be backed up by information they gathered for each key metric (clinical relevance, economics, and technical feasibility). After submitting their memo, each group reported their findings to the class in an informal presentation, and a group discussion was held as part of the module wrap-up. The module was implemented over three class periods, as shown Table 1 below.

Table 1 - Timeline of the newly developed module

\begin{tabular}{|c|l|}
\hline Class Period & Description \\
\hline 1 & Lecture notes, problem statement issued \\
\hline 2 & Teamwork \\
\hline 3 & Memo due, informal presentations \\
\hline
\end{tabular}

\section{Assessment}

In order to assess the impact of the new learning module, pre- and post-module surveys were developed and administered. The surveys were approved by the Institutional Review Board (IRB) at WNE prior to their use. To maintain confidentiality, students were randomly assigned a 6-digit code that was used to pair responses on the pre- and post-module surveys. The surveys consisted of technical questions (e.g., short answer and multiple choice) regarding the case study, including the key metrics for success in a global market, clinical relevance of diabetes mellitus, and the underlying physiology. The surveys also contained 5-choice Likert-scale questions that prompted students to rate their current level of knowledge/ability regarding twelve different 
EML skills (see Table 2 below). These skills were identified over several years of EML work through the KEEN network, and are based on the KEEN Student Outcomes (KSOs) [7, 11,12]. For example, many engineering courses have historically focused on technical design, beginning with specifications and ending with a prototype. The EML skills highlighted in Table 2 are intended to build on students' technical skills by allowing them to, for example, enter the project earlier in the design process (before specifications are developed) to explore market opportunities (i.e., investigate the market).

Pre- and post-module survey responses were compared using a one-tailed, paired-t-test with a significance level of 0.05 . Qualitative information was also gathered on the post-module survey in the form of free-response questions. Writing prompts were provided for these free-response questions, including learning/skill development in the module, what students liked about the module, and suggestions for improving the module.

Table 2 - EML skills investigated in the pre- and post-module surveys

\begin{tabular}{|c|l|}
\hline Number & EML Skill \\
\hline 1 & Identify an opportunity \\
\hline 2 & Investigate the market \\
\hline 3 & Create a preliminary business model \\
\hline 4 & $\begin{array}{l}\text { Evaluate technical feasibility, customer } \\
\text { value, societal benefits, or economic } \\
\text { feasibility }\end{array}$ \\
\hline 5 & $\begin{array}{l}\text { Test concepts quickly via customer } \\
\text { engagement }\end{array}$ \\
\hline 6 & Assess policy and regulatory issues \\
\hline 7 & $\begin{array}{l}\text { Communicate an engineering solution in } \\
\text { economic terms }\end{array}$ \\
\hline 8 & $\begin{array}{l}\text { Communicate an engineering solution in } \\
\text { terms of societal benefits }\end{array}$ \\
\hline 9 & Validate market interest \\
\hline 10 & Develop partnerships and build a team \\
\hline 11 & $\begin{array}{l}\text { Identify supply chains distribution } \\
\text { methods }\end{array}$ \\
\hline 12 & Protect intellectual property \\
\hline
\end{tabular}

\section{Results}

Of the 21 students in the course, 20 completed both the pre- and post-module surveys ( $95 \%$ response rate, $\mathrm{N}=20$ ). Student performance on the technical questions increased from an average score of $55 \pm 27 \%$ on the pre-module survey to $78 \pm 20 \%$ on the post-module survey ( $\mathrm{p}=0.002$ ). The results from the analysis of student responses to Likert-scale questions on the pre- and postmodule surveys are shown in Figure 1 below. When compared to pre-module responses, the post-module responses showed statistically significant increases in the following EML skills: 
- 2 - Investigate the market $\left(\mathrm{p}=7.4 \times 10^{-5}\right)$

- 3 - Create a preliminary business model $\left(\mathrm{p}=5.3 \times 10^{-5}\right)$

- 4 - Evaluate technical feasibility, customer value, societal benefits, or economic feasibility $\left(\mathrm{p}=2.9 \times 10^{-5}\right)$

- 7 -Communicate an engineering solution in economic terms $\left(p=6.4 \times 10^{-5}\right)$

- 8 -Communicate an engineering solution in terms of societal benefits $(\mathrm{p}=0.04)$

- 9 - Validate market interest $(\mathrm{p}=0.02)$

- 11 - Identify supply chains distribution methods $(\mathrm{p}=0.02)$

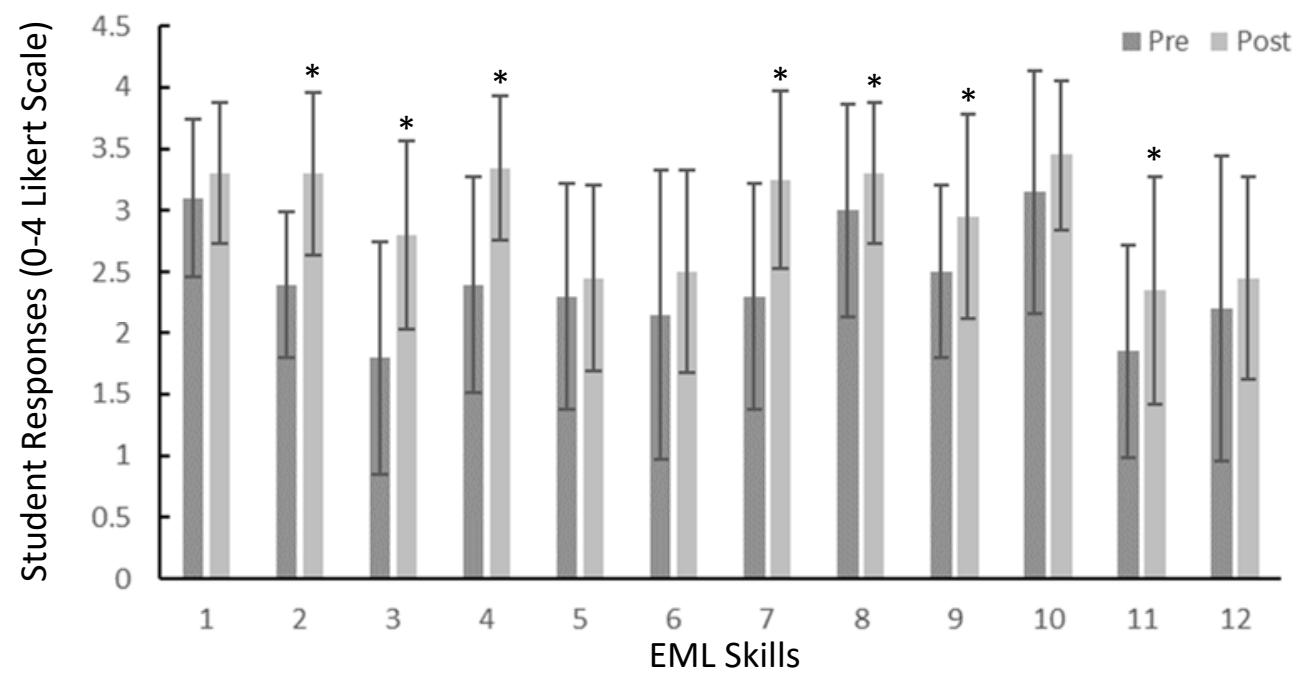

Figure 1 - Results from pre- and post-module surveys showing student reported confidence across 12 different EML skills (refer to Table 2 for description of each of the twelve EML skills).

The * indicates statistically significant differences between pre- and post-module responses.

The results from the qualitative free-response questions on the post-module surveys, including the question prompts and relevant representative student responses, are shown below.

Please comment on your overall development during this module (e.g., what you have learned, skills you have developed, etc.):

- Developed skills of understanding differences in global economy and adapting to meet them

- How to research a problem, dissect its relevance and calculate out its profit

- Number of individuals w/ diabetes worldwide

- It opened my eyes and made me realize producing and selling a medical device or any products is not as easy as it looks

- I learned how to research a country's economics and use that to see if a product is worth market share

- Learned how to research and assess a market 
- Good group dynamic, interesting to look into different markets

- This was a very interesting project that had us look objectively at a product and the market of it beyond the United States

- Learned how to view a possible market for expansion based on economic status and need for the device

- Learned how to compare markets based on economic factors

- I learned to look into how prevalent a disease is in another country in order to determine if marketing a device is worth the profit based on the country's GDP

- Determine whether or not a new market is possible within other countries

- What modifications can be made to make new markets possible

- Learned the 3 key metrics for success of a medical device

- Learned more on how to build a market analysis plan. Also more about other countries development in medicine

- The module was engaging. Allowed students to investigate markets

- I better understand the economics that goes into introducing a product to a new country

- More of a market side of engineering

- I think it helps put economics with engineering or a real world example

- I learned how to look at markets better

Please comment on the things you liked about this module, if any, and why you liked them:

- I have an interest in global markets and geography so taking that passion with passion with BME was dope

- I liked this project because it demonstrated the marketing and profit margin side of a product, not just its development

- Like the application to different geographical locations

- The knowledge of how the business world actually operates

- The research component because it allows you to see if a market is worth it or not

- I enjoyed the business side of engineering

- I liked that it was a team effort. It was quick and efficient to sit down and look at it as a team

- Enjoyed market analysis

- Interesting to compare other countries status to the US for the purpose of expanding a device market

- I liked how this took a concept we learned about and applied it to the real world

- I liked working with a group and finding out about another country and how they manage to help their diabetic patients

- Wide spread of countries

- Economic portion combined with clinical relevance

- I liked the skills area as it showed me what skills I am good at and what skills I should learn

- I liked working in a team, having class time to work on it

- Working in teams allowed multiple perspectives

- I liked learning the math behind how to price a product

- Different point of view gives a wider perspective 
- I liked talking about the pros and cons of entering an international market

- Looking at markets from the perspective of a company is interesting

Please comment on portions of the module, if any, that could be improved or changed:

- Greater differences in countries; while Brazil is more of an emerging country than Guatemala it's so cool to work in two at a time to actively compare

- Could improve the depth of the module to investigate deeper into the market

- More countries

- An economic/business lecture to clearly understand how to assess a market and make a business plan

- Maybe learn a little more about the physiology of diabetes

- Possibly doing a presentation to talk about findings with the class

- Say for the write up to be 2 pages the information didn't all fit on one page. Allow for estimate prices on manufacturing different components

- Do not do it in the last week, everyone is burnt out

- This could be a solo-project so everyone understood every part of the process

- There was literally nothing involving "protecting intellectual property" so why is that even an option on this survey

\section{Discussion}

The technical questions that were posed to students before and after the module involved a mixture of short answer and multiple choice problems. It is not surprising that the students would perform better on the post-module questions than the pre-module questions; however, these gains may not be solely attributable to the EML format of the module since no control group was able to be included in the study.

Regarding the EML skills that were targeted by this module, we were interested in investigating whether students showed gains in their self-reported EML skills. Additionally, we were curious as to whether those gains were in EML skills that were identified by the instructor as being directly linked to the activities in the module. The results from student-reported survey responses showed statistically significant gains in seven out of the 12 EML skills that were proposed/studied. Out of those seven skills, six were directly linked to the activities (see Figure 1). The one outlier was EML Skill \#11 - Identify supply chains distribution methods. This was not covered directly in the module, and thus can be treated as a false positive. Of the five skills that did not show statistically significant gains (see Figure 1), only one was directly covered by the module (EML Skill \#1 - Identify an Opportunity), which is considered a false negative.

When reviewing the student answers to free response prompts, a number of themes emerge. Regarding what students learned, several students commented on a connection to global markets, including important metrics for analyzing them. Moreover, the majority of student comments 
reflect EML skill development related to market opportunities and economic feasibility. With regard to the aspects of the module that resonated with students, multiple responses were received that mentioned enjoying the business and economics features of the module. As far as opportunities for improvement, students mentioned adding depth/time to further investigate the markets, adding more business/economic content to the notes portion of the module, increasing the number and diversity of countries to analyze, and changing the timing of the module to a different point in the semester.

Since the results from the first implementation of the new module were successful, it is expected that it will be continued to be implemented in future versions of the course after taking into account student feedback. The case study used in the first iteration could be altered to investigate alternative combinations of diseases and medical devices, enabling the instructor to implement the module at other points along the course timeline. For example, this course covers five major physiological systems: nervous, cardiovascular, respiratory, renal, and gastrointestinal. The module could be tailored to the nervous system by exploring the disease hydrocephalus and global markets for shunts, which are used in hydrocephalus therapy. Similarly, congestive heart failure and left ventricular assist devices could be explored for the cardiovascular system, asthma and spirometers for the respiratory system, kidney stones and ureteroscopes for the renal system, and ulcers and endoscopes for the gastrointestinal system. The module could be used in other BME courses as well with simple changes. For example, in a Biomaterials course, the combination of osteoarthritis and hip implants could be explored, and for a Bioinstrumentation course the pairing of atrial fibrillation and ECG could be investigated.

Additionally, the module could be tailored to other engineering courses outside of BME by changing the focus from a medical device to a consumer product. For example, in a circuit analysis course, global markets for cellular phone technology could be explored through the lens of global access to $2 \mathrm{G}, 3 \mathrm{G}$, and $4 \mathrm{G}$ networks. In a structures course for civil engineers, the module could be modified to explore markets for smart sensors incorporated in bridges.

Further details about the module can be found on the engineeringunleashed.com platform, including instructor resources, lectures notes, assignments, rubrics, and student surveys [11].

\section{Acknowledgments}

The author gratefully acknowledges the Kern Family Foundation (KFF) for its financial support of this project through the KEEN Institutional Grant at WNE. The author thanks Jennie Gilmore and Baylee Houldson with the College of Engineering at WNE for their administrative assistance with the pre- and post-module surveys. 


\section{References}

[1] R. Linsenmeier, D. Gatchell, "Physiology concepts and physiology problems for biomedical engineering students," Proceedings of the 2008 ASEE Annual Conference \& Exposition, Pittsburgh, PA, June 22-25, 2008.

[2] H.E. Gunter, M.A. D’Avila, S. Sadeghpour, R. Vijaykumar, J.V. Bonventre, "Educational innovation in physiology: Capillary filtration," Proceedings of the 2003 ASEE Annual Conference \& Exposition, Nashville, TN, June 22-25, 2003.

[3] J.L. Cezeaux, T.K. Keyser, "Introducing active learning strategies into an undergraduate engineering physiology course," Proceedings of the 2018 ASEE Annual Conference \& Exposition, Salt Lake City, UT, June 24-27, 2018.

[4] A.L. Gerhart, D.D. Carpenter, R.W. Fletcher, E.G. Meyer, "Combining discipline-specific introduction to engineering courses into a single multi-discipline course to foster the entrepreneurial mindset with entrepreneurially minded learning," Proceedings of the 2014 ASEE Annual Conference \& Exposition, Indianapolis, IN, June 15-18, 2014.

[5] E. Jablonski, "Fostering intra- and entrepreneurship in engineering students," Proceedings of the 2014 ASEE Annual Conference \& Exposition, Indianapolis, IN, June 15-18, 2014.

[6] KEEN Website [Online]. Available: http://www.engineeringunleashed.com

[7] J.A. Mallory, M. Romoser, M.J. Rust, T.K. Keyser, "Inclusion of entrepreneurially minded learning (EML) modules in $2^{\text {nd }}$-year core engineering courses," Proceedings of the 2016 ASEE Annual Conference \& Exposition, New Orleans, LA, June 26-29, 2016.

[8] N.K. Comolli, J.J. Elmer, "Entrepreneurial mindset (EML) modules for chemical engineering courses," Proceedings of the 2018 ASEE Annual Conference \& Exposition, Salt Lake City, UT, June 24-27, 2018.

[9] V.R. Mehta, D.R. Mikesell, "Implementing entrepreneurial-minded learning (EML) in a manufacturing processes course," Proceedings of the 2018 ASEE Annual Conference \& Exposition, Salt Lake City, UT, June 24-27, 2018.

[10] H. Park, "Fostering and establishing an engineering entrepreneurial mindset through freshman engineering discovery courses integrated with an entrepreneurially minded learning (EML) pedagogic approach," Proceedings of the 2017 FYEE Conference, Daytona Beach, FL, August 6-8, 2017.

[11] M.J. Rust, "Is there a global market for blood glucose monitors?" [Online]. Available: https://engineeringunleashed.com/cards/cardview.aspx?CardGuid=0adb727d-1429-400e-b1b5-5f7fb50ddd77

[12] D.E. Melton, "Stacking entrepreneurially minded learning alongside other pedagogies," ASEE Prism, vol. 28, no. 6, pp. 33-34, February 2019. 